December - 2006

\title{
Learners' Perspectives on What is Missing from Online Learning: Interpretations through the Community of Inquiry Framework
}

\author{
Emma J. Stodel \\ University of Ottawa \\ Terrie Lynn Thompson \\ University of Alberta \\ Colla J. MacDonald \\ University of Ottawa
}

\begin{abstract}
Despite the success that instructors and learners often enjoy with online university courses, learners have also reported that they miss face-to-face contact when learning online. The purpose of this inquiry was to identify learners' perceptions of what is missing from online learning and provide recommendations for how we can continue to innovate and improve the online learning experience. The inquiry was qualitative in nature and conducted from a constructivist perspective. Ten learners who had indicated that they missed and/ or would have liked more face-to-face contact following their participation in an online course were interviewed to elicit responses that would provide insights into what it is they miss about face-to-face contact when learning online. Five themes emerged: robustness of online dialogue, spontaneity and improvisation, perceiving and being perceived by the other, getting to know others, and learning to be an online learner. Garrison and colleagues' (Garrison, Anderson, \& Archer, 2000) community of inquiry framework was used to interpret the findings.
\end{abstract}

Keywords: Online learning; learners' perspectives; community of inquiry framework; cognitive presence; social presence; teaching presence

\section{Introduction}

Emerging technologies are offering alternative ways to conceptualise and deliver education and in the process are revolutionising how learners work, think, and build knowledge (Anderson \& Elloumi, 2004; McConnell, 2002; Salmon, 2000). Technology is becoming integral to the teaching-learning process as ongoing advancements offer new avenues for learning (Burge \& Haughey, 2001; DeBard \& Guidera, 2000). Online learning and the use of computer-mediated communication (CMC) tools are fast growing in popularity in higher education contexts (Burbules \& Callister, 2000; Kanuka, Collett, \& Caswell, 2002; Rovai, 2002). However, the adoption of this medium in the teaching-learning process has quickly outpaced our knowledge regarding how it might best be used (Garrison, Anderson, \& Archer, 2001; Garrison, Cleveland- 
Innes, Koole, \& Kappelman, 2006; Pawan, Paulus, Yalcin, \& Chang, 2003). This chasm in understanding needs to be bridged if we are to develop and deliver effective online learning.

The three authors have designed, developed, and taught graduate and undergraduate university courses online since 2002, as well as developed online learning for healthcare, the business sector, and international social development initiatives. This paper focuses on our work in the university context. We have extensively evaluated each class we have taught in order to improve the design and delivery of the course and gain insight into what makes an online learning experience successful. The courses have proved successful; learners indicated that they enjoyed the courses and met the learning objectives (MacDonald \& Thompson, 2005). Other indicators of success include strong university teaching evaluations, almost zero attrition, and twice receiving the WebCT Exemplary Course award. Despite the success of these online courses as assessed by these more common and obvious indicators however, learners often reported that they missed face-to-face (F2F) contact when learning online. The present inquiry was motivated by our intrigue to discover what it is about F2F contact the learners missed. That the learners were still longing for something when the obvious indicators of a successful course were present made this question even more captivating for us. Perhaps these indicators are not the only signs we need to consider when evaluating online learning. There is much to learn by delving into the experience of learning online. Understanding the online experience from the learners' perspectives by gaining insight into how, if at all, learners try to make sense of the 'disconnect' they feel due to lack of F2F contact provides important insights into how online learning environments can be better designed and facilitated. Consequently, the purpose of this inquiry was to identify learners' perceptions of what is missing from online learning and provide recommendations for how the online learning experience might be improved.

\section{The Concept of Presence when Learning Online}

Concerns surrounding the lack of physical presence in an online learning environment have led researchers to investigate the concept of presence when learning online (Bibeau, 2001; Garrison \& Cleveland-Innes, 2005; Tu \& McIsaac, 2002). Early work focused on social presence and the idea of participation and belonging (Garrison, 2006). Social presence is a factor that contributes to building a community of learners (Aragon, 2003; Bibeau, 2001; Garrison, Anderson, \& Archer, 2000, Rovai, 2002; Tu \& McIsaac, 2002) and some believe that social presence is one of the first components that must be established to initiate learning online (Aragon, 2003).

Social presence has been defined in a number of ways: "the degree of salience of the other person in the interaction and the consequent salience of the interpersonal relationships" (Short, Williams, \& Christie, 1976, p. 65); "the degree of feeling, perception, and reaction to another intellectual entity in the CMC environment" (Tu \& McIsaac, 2002, p. 146); "feeling intimacy or togetherness in terms of sharing time and place" (Shin, 2002, p. 122); "the ability of learners to project themselves socially and emotionally in a community of inquiry" (Rourke, Anderson, Garrison, \& Archer, 1999, \3); and "the degree to which a person is perceived as a 'real person' in mediated communication" (Gunawardena \& Zittle, 1997, p. 9). Social presence is closely related to the concepts of immediacy (Wiener \& Mehrabian, 1968) and intimacy (Argyle \& Dean, 1965). The purpose of an educational experience, however, is usually more than the development of a social community; the goal is to achieve defined learning outcomes and promote cognitive development. Garrison and Cleveland-Innes (2005) argued that if learning is to occur, interactions must be structured and systematic, rather than loose and social, and a community of inquiry must be developed. Creating a community of critical inquiry essential for higher order learning presents a challenge for educators teaching in an online environment where the communication 
medium is lean (Garrison et al., 2000, 2001). To help educators meet this challenge, Garrison et al. (2000) proposed a conceptual framework designed to guide the use of CMC tools to support critical thinking in education.

The community of inquiry framework developed by Garrison et al. (2000) is based on a model of critical thinking and practical inquiry. Garrison et al. (2000) suggested that learning occurs through the interaction of social presence, cognitive presence, and teaching presence within a community of inquiry that is composed of teachers and students. Based on content analysis of postings in asynchronous discussion forums they proposed a number of indicators for each type of presence (Anderson, Rourke, Garrison, \& Archer, 2001; Garrison et al., 2001; Rourke \& Anderson, 2002; Rourke et al., 1999).

Garrison et al. (2001) defined cognitive presence as "the extent to which learners are able to construct and confirm meaning through sustained reflection and discourse in a critical community of inquiry" (p. 11). Based on Dewey's (1933) concept of practical inquiry, Garrison et al. (2001) delineated four phases of practical inquiry: triggering event, exploration, integration, and resolution. The second element of Garrison et al.'s (2000) framework is social presence, which they defined as the "ability of participants . . . to project their personal characteristics into the community, thereby presenting themselves to other participants as 'real people"' (p. 89). The function of social presence is to facilitate the attainment of the cognitive learning objectives by supporting critical thinking in a community of learners, as well as the affective learning objectives by making the group interactions enjoyable and rewarding. Rourke et al. (1999) suggested that social presence in CMC is reflected by three categories of postings: affective, interactive, and cohesive responses. Finally, the last element in the community of inquiry framework is that of teaching presence, which supports and enhances social and cognitive presence and is "most directly under the control of teachers" (Anderson et al., 2001, p. 3). There are three categories of teaching presence: design and organisation, facilitating discourse, and direct instruction.

Given that some learners in our online courses reported they missed F2F contact when learning online, the purpose of this inquiry was to identify learners' perceptions of what was missing in their online learning experience. As physical presence is absent in an online environment, a theoretical model of online presence - Garrison and colleagues' community of inquiry framework (Garrison et al., 2000) - was chosen to allow us to interpret the findings from a theoretical perspective.

\section{Methodology}

\section{Context}

Introduction to Research in Education is one of ten courses learners must take to complete the M.Ed. program at this Canadian university and was designed to prepare learners to consult and use research in education. It is one of two courses learners can take online. At the time this research was conducted, the online and F2F versions of the course were offered in alternating semesters; therefore learners wanting to take the course in a particular semester were not able to choose the delivery format. The first and last authors designed and co-taught the course.

The first of the 13 units in the course was delivered F2F in a three-hour session that provided an overview of the course and an orientation to the technology. There was an additional optional F2F session in the second week of class to provide additional assistance to those students who wanted 
it. The remainder of the course was delivered completely online using WebCT. While this course included a couple of F2F elements, and therefore could be perceived as a blended course, it was first and foremost an online course and regarded as such by the learners, instructors, and faculty. The email, discussion forum, and chatroom communication features of WebCT were utilised. Discussion forums were created for each unit, except one. Ten percent of the learners' final grade was based on their professional participation in the course. Learners were informed they were expected to act as learning consultants to each other by providing support and feedback on each others' work, be prepared to actively participate in the discussions, and facilitate one of the discussion forums as part of a facilitation team. The remaining 90 percent of the learners' grades came from written assignments they submitted to the professor for grading. Optional chat sessions were held with the professors every two weeks to provide the opportunity for real-time communication. Learners could use these sessions to socialise with the professors or ask questions regarding the course content.

Learners were guided through the course by an eSyllabus and a RoadMap that explained the course activities (e.g., readings, discussions, assignments) for each unit. Links from the RoadMap enabled learners to access the pertinent resources. Text-based e-Docs were constructed to deliver the course content and numerous support resources were included in the learning environment. To help learners orient themselves to the technology a series of activities using the WebCT CMC tools was created that learners completed in the first week. One of these activities was to create a learner page where learners introduced themselves to the class.

The learners in the course were grouped into triads and expected to provide support and constructive feedback on assignments to their triad members. Learners self-selected triad members during the initial F2F session. As part of the course requirements, each triad was required to e-moderate one discussion forum. The professors determined the general area for discussion each week and provided relevant readings and online documents. The e-moderators (learners) then developed the discussion questions and took the topic in any direction they chose as they facilitated a one-week dialogue between their peers. Learners were provided with guidelines for facilitating online discussions.

\section{Participants}

One of the final course requirements necessitated the learners to reflect on the course and share their experiences by posting a final reflection in the discussion forum. The final postings suggested that, overall, the learners enjoyed the course and had a positive experience. However of the 23 learners in the course ( $n=3$ males; 20 females), 11 reported that they missed and/ or would have liked more F2F contact. In an attempt to understand what it is about F2F contact the learners missed, these individuals were invited to participate in an interview. Ten of the eleven learners ( $n=1$ male; 9 females) accepted the invitation and agreed to participate in this inquiry. The majority of the participants were working adults who were teachers, school administrators, or counsellors, the remainder were full-time students. The cultural diversity of the class was reflected in the participants in this inquiry. All the participants signed a consent form.

\section{Procedure}

The inquiry was qualitative in nature and conducted from a constructivist perspective. Constructivist proponents "share the goal of understanding the complex world of the lived experience from the point of view of those who live it" (Schwandt, 1994, p. 118). Each participant engaged in an in-depth semi-structured interview; the purpose of which was to 
discover what the learners perceived was missing from online learning and what they felt would make the online learning experience richer. The interviews were audio-taped with the participants' permission and then transcribed verbatim. The transcripts were returned to the participants who were asked to read, amend, and expand them if they felt it would clarify or better represent their answers.

\section{Data Analysis}

Data were analysed using the constant comparative method (Bogdan \& Biklen, 1998; Merriam, 1998). The first interview transcript was read and re-read and notes, comments, and observations were written in the margin with regard to interesting data that were relevant to developing an understanding of what was missing from online learning for that participant. A preliminary list of emergent categories into which the notes and comments were grouped was developed. The second interview was then analysed in the same way as the first, and the two lists of categories were compared and merged to create a master list. This process was repeated until all the data had been analysed. Once the authors were satisfied with the categories, the data were fractured into meaning units that were assigned to the categories. Direct quotations were used throughout the report in order to preserve the voice of the participants. Pseudonyms were assigned to maintain the participants' anonymity. The findings were then interpreted using the community of inquiry framework.

\section{Findings}

Five themes regarding what learners perceived was missing from their online learning experience emerged: robustness of online dialogue, spontaneity and improvisation, perceiving and being perceived by the other, getting to know others, and learning to be an online learner.

\section{Robustness of Online Dialogue}

Participants focused on issues relating to the online dialogue, in particular, the comparison to F2F conversations and controlling the flow of the online discussions.

\section{Comparison to F2F}

The learners varied in their perceptions of the quality of online discussions. Katie recognised that after people had figured out the technology and "got more comfortable with it then the quality of the discussion got better and better all the time." Others, however, felt that the quality of the discussions was poor and that occasionally the forums were used as a means of "reporting in" rather than as a medium for discussion. Molly noted, "I'd respond to something and then . . . somebody would respond to the same thing but didn't respond to my [comment] . . . I don't think people were always . . . paying attention to other participants . . . that was a little frustrating [and] ... inhibited the conversation." On a similar note, Katie felt discussions were drawn out and there was a lot of "rehashing":

"In the classroom, I think you would tend to cut that short . . . you'd say, 'Is there anything more to say about this topic? No, let's move on.' I think because it is online and you're thinking and typing it tends to get drawn out more." 
Conversely, Fran felt that communicating through text constricted the conversation: "You can say a lot through speaking. You change your ideas fast, and the body language and the expressions. You can convey faster and in a bigger way; your ideas can be more."

Some learners felt that a robust online dialogue was missing because the "dynamic" that is often present in F2F settings was missing. Ann explained, "Someone else's comment will inspire you to make another comment and then the conversation has a certain dynamitism to it ... In the online discussions . . . people would comment but [there was] the time [lag] or people wouldn't answer." Whether this desired real-time communication had to be F2F or not was a question contended by the participants.

A number of learners missed the energy of F2F classes. Learners talked about being able to feed off other people's energy in F2F settings and feeling more energised after F2F classes. One missed the humour that can be used to break tension in F2F classes:

"Someone comes up with a quick one-liner and everyone laughs and relaxes and the tension is broken. At home you're the only one that can break the tension . . . so if you're not in the right mindset you're going to get more tense reading it . . . There is no opportunity to take a breath with everyone as a group, for everybody to take a step back and take a deep breath and say, "OK, we can't be this serious about it" (Molly).

Some learners indicated that they missed the emotion that is usually present in F2F interactions, although many agreed that there was emotion present in the online course. Katie reported that she made an effort to include emotion in her postings. Nevertheless she cautioned: "When you are writing you can get a certain amount of emotional impact in your writing, but what you put into it someone else may or may not detect." It is likely, however, that not all learners will be able to inject such emotion in their postings. Katie noted, "To me, the written word is such a powerful thing and that's probably where I've had some negative aspects of this . . I mean email messages are just so grammatically incorrect and flat."

\section{Controlling the Flow}

In this course, the primary form of online communication was asynchronous (discussion forums and email) but there were also opportunities for synchronous communication (chatrooms). Many learners commented that the communication through the discussion forums was more reflective and they benefited from this. Learners noted they put more thought into their postings and were able to express themselves more clearly. They liked to be able to slow the pace of communication and clarify points when necessary and/ or go back and review postings. Moreover, Maire stated, "I never felt bored with [the conversation] because I knew I could depart from it whenever I wanted."

All but one of the participants commented on the absence of non-verbal cues. Kelly was nervous that she would post something that someone would misinterpret because it could be taken out of context without such cues. Learners in this inquiry struggled to understand the silences. Although there was a perception of feeling connected to others, some learners still had a sense of isolation on occasion. One factor seemed to be "a lack of responsiveness on the part of the class to one's comments." Without the non-verbal communication there is no (or minimal) feedback in terms of how well you are communicating. As Katie commented: 
"You know when you've put your foot in your mouth when you're talking to someone $[\mathrm{F} 2 \mathrm{~F}]$. . . but when it is online, it's not quite the same . . . There are some times when things are said and, yes you get those sharp responses back, but ... it's easy to just ignore."

\section{Spontaneity and Improvisation}

Learners reported there was a decreased tendency for the discussion to go off on a tangent and a lack of spontaneity in the course. Learners' feelings regarding this were mixed. Although Lisa liked to self-scrutinize herself before she spoke, she also valued spontaneity: "[What] I like about the classroom and the teacher is the tangent factor; those teaching moments where it's not on the syllabus but it's kind of important or a nice touch." The lack of spontaneity was also a negative aspect of the course for Maire:

"I find in a F2F class . . . a lot of the learning happens just through discussion; like when you're sitting around and somebody brings up a point and that leads to another point and you have this discussion that comes out of nowhere . . . I found with this I could read something and I might have an initial reaction but at the time I don't have time to type it out and when I come back to it I've kind of lost my groove and just don't post."

Indeed, having to take the time to compose a message rather than being able to just speak your thoughts prevented more than one learner from participating as much as they might have in a F2F class.

There were some learners who felt they would benefit from more synchronous communication, perceiving that it was more "real". Rick liked synchronous communication because "the conversation can move along more quickly." He elaborated, "I like to interact, not be passive. And I think most people also feel they ... . want to give some feedback back. It is a shared experience that they are looking for." A number of learners talked about the frustrations associated with having to wait for a response to a question from other learners, especially if the information that was returned was not what the learners wanted. One learner explained:

"If it is in real-time and they misunderstood you, you can correct them at once . . . It's kind of a helpless feeling; you're yelling at your computer, 'It's not what I'm saying, it's not what I wanted you to respond to.' But I have waited for three days or a week [for an answer] . . I I want to learn more efficiently" (Lynn).

Despite the desire for more synchronous communication, however, The Chatroom - the one tool that supported synchronous interaction in this course - was not very popular. Many commented on how hard it was to have a conversation through this medium. One learner noted that she could not type fast enough and would have appreciated having sound attached to the chatroom, noting: "For me, listening and talking is much faster than writing and reading" (Zoe).

\section{Perceiving and Being Perceived by the Other}

Learners in this inquiry were conscious of how they perceived others and how others perceived them online. Furthermore, the "accuracy" of the images they constructed was questioned. Concerns regarding honesty also emerged. Katie stated, "I like to look at a person right in the eye 
and see if they are honest and you can't do that with a computer." Rick felt that not all the learners portrayed themselves accurately online. He indicated, "People would often put things in the best of light in their online communications and then not necessarily follow through." Furthermore, Rick felt that it was important that learners include a picture of themselves on their learner pages. He explained:

"I do think in learning communities there is an expectation of honesty and part of the honesty for me is being able to know who I'm dealing with, just to be able to see what they look like. I felt there was a reason why people didn't put their pictures up there."

Also, participants felt they were in a position where they had to make assumptions and believed that it was human nature that other learners would try and read between the lines. Kelly noted:

"When you're online you can make it what you want it to be, because there is a part of it where you're being creative. You're imagining who these people are and you're imagining what they're like and what their personalities are like. You don't really know until you meet them."

A number of learners commented that they thought they came across differently online compared to F2F.

The learner pages helped facilitate the development of relationships, making the online experience rich. One learner commented, "Those were really helpful because you did get a sense of who the people were ... . And you could go back [and see] 'What does that person look like?"' A number of learners, however, commented that some of their fellow learners remained "faceless." In some instances this was because they did not include a picture of themselves on their learner page. One learner relayed why he felt this was a problem:

"[If] you've seen their face, you know who they are so if you see them again in a conference or in another course you can immediately build on that relationship. But . . . with someone who hasn't posted a picture, I could . . . sit right next to them and not realise that's who they are" (Rick).

Learners were conscious of not posting something that might offend others. One learner felt that this might change as people get more experienced using the technology. This led to some banal conversation, however. As Molly put it:

"I do think that [the interactions] were . . . bordering on the ridiculous sometimes in terms of praise. I mean you don't praise people that much in a face-to-face situation, so why would you merely because you're online? The constant 'Good work', 'Good thought'. What really detracted from the so-called reality of the interactions was this virtual sense of touchy-feely camaraderie. Few people participated in head shaking, in disagreement, which is what makes a discussion flow."

Learners also commented on the formality of the communication, which resulted, at least in part, because the learners felt they needed to put a lot of thought into the postings because of their permanence. Learners wanted to sound academic so would take care to include references, check spelling, and carefully select the right words to use. 


\section{Getting to Know Others}

The degree to which the learners felt they were part of a community seemed to be influenced by the social relationships they developed with each other and the professors. The learners varied in their success at developing friendships with other learners in the course. Ann reported, "Generally I come up with really good friends at the end of courses and that is also an enriching process for me. It didn't happen this time." Although she wanted more F2F contact with her triad and the other two triad members met frequently, Ann only met with her triad a couple of times because she found it inconvenient. She felt the lack of time they met F2F hindered them from developing a social relationship. Ann found when they did meet they were very task oriented and there was little time for socialising. Lisa also felt that she did not "really get to know people" in this course yet commented that in previous online courses she had got to know people better. She attributed this to different course content and that there was not a centralised topic of interest, but instead many different research areas the learners were interested in, as well as the fact that in the other course the learners were "excited to get into a hot discussion about [the topic]." She also felt that the discussions never got "to a critical thinking level" for the same reason. Nonetheless, topics that had a lot of potential for discussion and where the e-moderators attempted to post thought provoking questions and controversial statements still did not generate the discussion many of the learners hoped for.

In contrast to these learners' experiences, Lynn developed a very close friendship with one of her triad members. Similarly, Rick noted, "One of my surprises was that you could actually bond with people online that you haven't met face-to-face." The depth of the relationships developed also varied. Maire explained, "I didn't feel that I developed relationships with people [even though] I certainly found out more about my classmates than I ever have [through the learner pages]." Conversely, Molly felt "There is more room in face-to-face situations for [informal] information to come out."

Learners felt there was a sense of community between and among the learners and professors. Learners felt supported and encouraged in their learning. There was a sense of caring and learners indicated that people were usually quick to help, share resources and information, and respond to questions. Fran explained, "The beauty of it is that we have all these people that you could easily connect to ... I think for adult learners like myself that have a minimum time to spend, this is very good." The community served a purpose outside academics; there was also a sense of personal caring. For example, one learner posted in the forum warning about the perils of tobogganing after her friend broke her back. Maire relayed, "I thought, 'That was really nice, it goes to show that we are here for more than just this class.' And it sort of showed that people still do need that interaction aside from just the academic." Katie attested that the biggest factor that contributed to the development of the community was the sense of camaraderie between the professors.

Learners had mixed feelings with regards to the type and depth of relationship they felt they had developed with the professors and the type of relationship they wanted and/ or expected. Some of the learners felt they did not benefit from the professors' expertise in the online course. Ann noted that she would have liked to have met the professor F2F to "get her insights into the material informally ... I mean just her insights as a person, as someone who has done research for so many years, we just never had that." Indeed, many of the learners missed the informal conversations they might have had with the professors if the course had been F2F. These conversations appeared to be as important for relationship building as for learning. 


\section{Learning to be an Online Learner}

Many of the learners did not feel confident about engaging in online learning. For most, this was their first experience learning online and they were concerned that they were not "doing it right." Some were worried they were "missing something" or "were behind and didn't know it." A number of the learners wished there was F2F contact as they felt that would have allowed them to see if they were on the right track. Learning online they felt they had no one to ask, "Am I doing this right?" Learners felt they missed "[picking] up on the small points you get through informal conversations" with classmates or dropping into the professor's office after class. Fran noted, "[Human contact gives you] reassurance." Other learners felt that meeting F2F would allow the sharing of experiences of learning online and perhaps "boost their confidence." Indeed, at least one learner sought out opportunities to discuss her experiences F2F with other learners and used the F2F classes she had with other learners to reassure herself she was on the right track with this course.

A number of the learners were worried about making postings in the course. Fran described, "I had a panic attack! Although people couldn't see me, the idea of just sending something in writing was like . . . all these people could read what I put down! [It] was a very fearful situation." Learners were concerned that what they wrote would be judged and they would not sound academic enough. Maire noted, "I think that was more of our personal insecurity; we're not going to put our dumb old comment on there because there's some really smart sounding ones on there." Similarly, Fran relayed, "A lot of time I was very skeptical to jump in at first because I felt maybe I'm wrong . . . just the idea of putting my writing in the middle of all these people and them seeing it." A number of learners wished there was the facility to edit the discussion postings. One learner noted, "It was just so final; you put it out there and you couldn't change it. I think that probably influenced how I wrote things and what I said."

\section{Discussion}

We used Garrison et al.'s (2000) community of inquiry framework to interpret the findings and help us understand what these learners missed in their online learning experience. The findings will be discussed within the three areas of presence identified within the framework: social, cognitive, and teaching. It should be noted that due to the interaction of these three elements, as indicated in the framework, many points of discussion span more than one element.

\section{Cognitive Presence}

According to Garrison et al. (2001), cognitive presence reflects higher-level knowledge acquisition. Examining our findings through the lens of cognitive presence fostered a deeper understanding of the learners' experiences and actions online and provided insights on how critical thinking and cognitive presence can be enhanced.

Internet practices create a reality of nowness and immediacy; other people, information, and events are just a click away. However, in this course it was the lack of immediacy -- the spontaneity and quickness of a F2F learning experience -- that the learners missed. Although learners enjoyed being able to reflect on their postings, they spoke of the inability to pursue tangents like they would in a F2F conversation; the spontaneous teaching moments that are not prescribed by the syllabus. Furthermore, the asynchronous nature of the conversation meant that by the time they composed a response to a posting they had "lost the groove". Our findings 
illustrate the non-linear cognitive process that appealed to these learners and their desire for the freedom to explore and tackle interesting and learner-generated problems and issues; a process that they believed was more easily enabled in a F2F setting.

When designing online learning events, Cavallo (2000) argued that delivering a pre-set curriculum does not take "advantage of the very benefits that . . technology affords" (p. 774). Thompson and MacDonald (2005) explored the tension between structure and flexibility in design. They found that a well mapped out course seems to increase learners' competence and confidence, yet recognised that course design needs to have the flexibility to respond to emerging learning needs. They concluded that a course that lends itself to rapid redesign as learners' needs become better articulated leads to a quality learning experience. The voices of the learners in this inquiry further emphasise the importance of emergent design and facilitation-the ability of the online learning experience to respond to and even drive evolving and budding tangents as they surface. Further research is needed to better understand how technology can be used more effectively (and innovatively) to open up tangents that may lead to more cognitive presence and movement through the critical thinking process as outlined in the community of inquiry framework.

The data in this inquiry reflect a jumble of perceptions and expectations about what learners do in online discussions. Some commented that the discussion forums were used merely to report in and not as a medium of discussion. To some the discussions were too loose and drawn out. To others the discussions did not progress. At the same time, these learners seemed to value the reflective nature of the postings. Other researchers have encountered similar findings regarding learners' experiences with discussion forums. Thomas (2002) found an overall incoherence in online discussion in terms of "branching structure, the large proportion of messages that terminated branches, and the abstracted nature of student interaction" suggesting that "the online discussion forum does not promote the interactive dialogue of conversation, but rather leads students towards poorly interrelated monologues" (p. 361). Others, such as Pawan et al. (2003), have found parallel results. Levy (2003) noted that contributing to online discussions is often one of the most challenging aspects of online courses. It entails "learning a different form of communication" and sometimes can feel like "anything but a conversation" (Levy, p. 102). Although CMC tools are still evolving, current practices suggest that online communication can be disjointed as learners jump in and out of online discussions. Our data reveal the paradox of online communication in that it is more informal and more formal than F2F conversations; more frenetic and more reflective. Garrison et al. (2000) stated that the "extent to which cognitive presence is created and sustained is partly dependent upon how communication is restricted or encouraged by the medium" (p. 93). Our findings add to the research literature that highlights the contradictory and ambiguous nature of online discussions in an academic setting.

Anagnostopoulos, Basmadjian, and McCrory (2005) asserted that within a F2F classroom teachers and students do not "expect to define social space and interactions . . . they expect to find their place within it" (p. 1699). This is in contrast to online classes in which teachers and students may share few expectations and conventions. It seems learners in this inquiry had varying expectations of how the discussions fit into their learning path and therefore the usefulness of these forums to their learning. The findings suggest that for some learners their perceptions of the purpose of the discussions was merely a way of reporting in - a façade of participation. In contrast are lively online discussions that enhance, are an integral part of, and reflect learning. The findings encourage us to question whether these learners wanted to engage critically in online discussions and whether they regarded the discussion forums as the best venue for this type of dialogue. As Thomas (2002) noted: 
While the online discussion forum has become a ubiquitous element of Internet-supported flexible delivery of education, it is apparent that it might not be the best technology to support the interactive and collaborative processes essential to a conversational model of learning (p. 364).

Critical thinking in an asynchronous text-based online learning environment is not necessarily reflected entirely in the postings. Certainly, findings in this inquiry suggest that learners engaged in critical thinking with other members of their triad offline. In addition, learners likely engaged in critical thinking in their own reflections, in dialogue with colleagues outside the course, and in their assignments. Garrison and Cleveland-Innes (2005) observed that students may be "cognitively present while not interacting or engaging overtly" (p. 144); for example, when vicariously following and reflecting on the discussion and constructing meaning individually. Moreover, the learners in this inquiry shared the careful nature in which many of their postings were constructed. They did not want to post something that might offend, they wanted to sound academic, they were excruciatingly aware of the permanence of whatever text they posted, and they did not feel fluent in the language of online dialogue. Given these concerns it is perhaps not surprising that the learners did not engage in a higher degree of critical thinking in the forums; its very nature demands an unpacking of assumptions and a willingness to expose personal beliefs, tease apart differences, and challenge assumptions. It is therefore problematic to equate the presence of critical thinking solely to what transpired in the discussion forums.

Using the community of inquiry framework to interpret the findings in this inquiry elicited questions regarding the intentions of this particular online learning experience. Was it to create a collective community of inquiry; for the learners to engage in all four stages of the critical inquiry process? It seems the forums were used to build a sense of community in order to help learners achieve a level of critical thinking made evident in their individual papers. We also need to question who the "collective" is in an online experience: the whole class? the triads? Perhaps for some there is no collective.

\section{Social Presence}

There is no doubt that learners felt a degree of social presence within the course. Social presence appeared to be greater within the triads than for the class as a whole. Perhaps the more frequent interactions that occurred in these small groups led to a greater sense of presence (Russo \& Campbell, 2004). There was some evidence for social presence in each of Garrison et al.'s (2000) categories of social presence: emotional expression, open communication, and group cohesion. In the category of emotional expression, there were indications of self-disclosure on the learner pages. Learners shared wedding pictures and photographs of their children, travel stories, hobbies and professional interests, and likes and dislikes. Learners felt they knew more about more of their classmates than they would have if the class was taught F2F. However, we feel it is important to distinguish between getting to know about someone and getting to know someone and propose that it is the latter that contributes to social presence. There was scant evidence of other indicators of emotional expression; the learners in this inquiry generally felt that humour was lacking in the course and they rarely used emoticons in their postings.

According to Garrison et al.'s (2000) definition, there was evidence of open communication occurring between learners in the course. Learners responded to each others' messages; quoting from previous messages and continuing on a thread. Learners signalled agreement with each other and asked questions. However, some learners got frustrated with the constant agreements and comments such as "Good point" and "I agree"; feeling it made the conversation overly positive and fake. Although these types of responses and rejoinders are an important component of 
conversation as they build relationships and provide encouragement (Eggins \& Slade, 1997), they were not valued as such by the learners in this inquiry. There appears to be a fine line between the need for these types of comments to build and sustain community and avoiding their overuse to the point of being annoying. There is a need to post comments that challenge and provoke learners to reflect and construct new knowledge thereby stimulating in-depth discussion. This type of discourse was only apparent a few times in this course. Perhaps this led learners to disengage as they did not feel challenged or inspired by their peers. Indeed, Anderson (2004) noted that an "absence of social presence leads to an inability to express disagreements, share viewpoints, explore differences, and accept support and confirmation from peers and teacher" (p. 274). The link between cognitive and social presence is apparent here and invites us to ask whether educators' efforts should first be focused on developing social presence or on encouraging learners to engage in meaningful discourse, or whether these two elements need to be developed in concert. Fostering social presence might be a necessary precursor to meaningful discourse, but if the "conversation" comprises only social dialogue and low level information exchange then perhaps learners will disengage as they perceive they are "wasting time" getting to know each other and are not learning.

Group cohesion was evident in that the learners helped each other out by answering questions that related to technical problems and course requirements and shared resources they thought others would find helpful. They looked out for each other; warning of the perils of tobogganing after one learner's friend broke her back. Yet learners commented that the bond with other learners was not as strong as it would have been in a F2F class, where learners are likely to meet after class to go for coffee or walk together to their cars or the bus stop and talk about life. It seems that the social contact time between learners is higher in a F2F situation than online. However, there is the potential for contact time to be much greater online given the characteristics of the environment. Perhaps learners do not take advantage of this because they see online learning as a convenient and efficient way to learn and therefore when they log onto the course they view the goal as learning, not idle conversation and developing social relationships. Maybe the individuals most attracted to online learning are those who are "surface learners" and focused on "getting it done" (see Garrison \& Cleveland-Innes, 2005 for a discussion on deep and surface learners). Future research analysing what learners do with their time online is warranted.

Although there were indicators of social presence within this course, it appears that this is still what the learners missed most when learning online. Lynn noted, "I just want to have the feeling that the communication is real and that I [am] talking with a real person in real time." Learners reported that when they read postings they sometimes questioned who wrote them, a problem also experienced by learners in Tu and McIsaac's (2002) study. With the use of WebCT discussion boards comes the standardisation of messages. That is, the variation in the appearance of messages is minimal and so messages become generic and less personal (Shamp, 1991). Although emoticons and different font styles can be used, learners are limited in how they can represent their thoughts beyond words. These constraints are less evident in technologies that use voiceover-IP capabilities thereby enabling the learners to inject more of who they are into their communication. Other technologies, such as Moodle, allow the inclusion of a personalised image next to postings, which would help develop a connection between the posting and the person who wrote it.

A common perception among the participants was that learners remained faceless. A few learners noted that they could easily get annoyed at postings and attributed it to not being able to associate the posting with a face. Two learners described yelling at their computers out of frustration because of something that was posted, rather than at the person who wrote it. The concept of 
anthropomorphism within the context of online learning has been discussed in the literature (Rourke et al., 1999). Increasing social presence is likely to reduce the application of anthropomorphism to computers and strengthen the identity of the learners.

Perhaps the learner who was most successful in establishing her identity in the course was one whose postings were written as poems, demonstrating a stylistic communication style. Her postings always evoked numerous responses. Such a distinguishing style gave this learner an identity within the group and arguably increased her social presence within the course. The relationship between identity and social presence has received scant attention in the literature. Rogers and Lea (2005) examined whether establishing a personal identity is necessary for social presence or whether it can be realised through the creation of a shared social identity. They suggested that social presence can exist within a group when the group has common goals and a social identity exists, regardless of whether there are interpersonal cues and learners are able to portray their personal identity. Consequently, they proposed that in a distributed group (such as the one in this course) the focus should be on making the shared social identity salient, rather than the personal identity, so group goals, priorities, and norms are adhered to, rather than individual ones. As a result, the lack of interpersonal cues resulting from an absence of F2F contact will not be a barrier to developing social presence (Rogers \& Lea).

Enormous efforts were made to foster social presence during the design and delivery of this course using multiple strategies, including learner pages, welcoming postings, learning triads, chat sessions, discussion forums, a F2F orientation class, small class size, collaborative activities, promptly responding to emails and postings, sharing personal stories and experiences, and being funny, many of which have been suggested by other educators and researchers (Aragon, 2003; Gunawardena, 2005; Lobry de Bruyn, 2004; Russo \& Campbell, 2004). Yet despite these efforts, we feel that perhaps more can be done to enhance social presence in online learning. One way to do this is to explore the role of emerging technologies in this regard. Text-based communication is time consuming. Responses need to be constructed and then typed. Visual cues get lost so learners take extra care regarding how they structure their postings to ensure they are not misconstrued. The time factor sometimes means that learners do not say everything they want to. Interactive Voice Response (IVR) systems that will type the spoken word may reduce the time required to construct postings.

In addition, the integration of audio and video technologies will allow the creation of a richer communication medium that contains more interpersonal cues to enhance social presence. Webbased video conferencing is becoming more and more prevalent requiring only an inexpensive Web-based video camera and the download of free software, such as MSN Instant Messenger or Skype. Even the use of audio without video, requiring less bandwidth, may contribute to social presence. The use of short, multimedia rich "digital movies" that include pictures or video of the professor or a learner, along with his/her voice, to present ideas may also serve to enhance social presence. Application sharing software is also becoming more popular and is available at no cost (e.g., Windows Messenger). Application sharing allows two or more users to work on the same application at the same time from one computer, regardless of their location. Again, this approach would likely enhance social presence. Research that investigates the use of these types of software to foster social presence and enhance online learning is required.

The use of synchronous communication options to enhance social presence is a point of debate. Haythornthwaite, Kazmer, Robins, and Shoemaker (2004) argued that synchronous communication contributes to community building and "provides simultaneous many-to-many contact that helps stave off feelings of isolation" (p. 48). Wang and Hewlin (2001) found that 
chatrooms enhance social presence in a way that cannot be achieved by asynchronous communication by affording the possibilities of immediate feedback and answers to questions; providing encouragement; and fostering learner perceptions that the educators are genuinely invested, engaged, and personally connected with the learners. Moreover, the learners in this inquiry reported they missed the dynamic nature of synchronous communication and being able to steer the conversation. However, the inclusion of synchronous components in an online learning experience takes away the features that attract many learners to this medium: the convenience and flexibility afforded by not having to meet at a specific time and place. Indeed, Anderson (2004) reported, "I have noticed a deep division between those who yearn for the immediacy of real-time communication, and those who are adamant that they have chosen online learning alternatives to avoid the time constraints imposed by synchronous . . . activities" (p. 279). Learners need to carefully assess why they have chosen to learn online, rather than F2F, and determine whether they are ready and willing to adjust to learn in this new type of environment that is fundamentally different from a F2F setting.

The style of communication can impact social presence (Russo \& Campbell, 2004). It is an art to be able to express yourself through text. As educators, we need to spend more time teaching learners how to communicate, collaborate, and build community effectively online if we want to enhance social presence. Learners felt that the communication was more formal online than it would have been F2F, which appeared to diminish the sense of presence. Tu and McIsaac (2002) found that when postings are more formal, immediacy is sacrificed and perceptions of social presence decreased. Similarly, others have found that learners are able to increase presence when they are less formal, write in more conversational tones, and make jokes (Russo \& Campbell). A balance must be achieved between the need for the professionalism required in a university setting and the need for informality required to enhance social presence. Furthermore, in addition to the instructional and conversational voices typically seen in online transcripts, Stroupe (2003) discussed the need for a compositional or third voice within which "students play an active role in creating, or composing, not just their own texts, but the experience of the class, its sources of authority and presence, and its online community" (p. 258).

\section{Teaching Presence}

The community of inquiry framework proposes three indicators of teaching presence: design and organisation, facilitating discourse, and direct instruction (Anderson et al., 2001). Throughout the course and during the interviews, learners repeatedly commented on how organised the course was. Our experience designing, developing, delivering, and evaluating online courses has made us cognizant of the importance of design to the quality of an online event (MacDonald \& Thompson, 2005; Rovai, 2003; Salmon, 2000; Song, Singleton, Hill, \& Koh, 2004; Thompson \& MacDonald, 2005). Designing and developing quality online courses takes an enormous amount of time as well as painstaking attention to detail (Anderson et al., 2001; MacDonald \& Thompson, 2005). This course was no exception. We were also aware that using learning models helps "address realistic applications of new knowledge in context" (Garrison \& Anderson, 2000, p. 28). By using the Demand-Driven Learning Model (DDLM) (MacDonald, Stodel, Farres, Breithaupt, \& Gabriel, 2001) to guide the design and delivery of this course it would appear that many of the design issues that may otherwise arise in an online course were addressed prior to delivery. The present research inquiry reinforces the importance of design and organisation in successful online learning.

In terms of facilitating discourse, Rourke and Anderson (2002) and Anderson (2004) extolled the benefits of having the learners take on the role of discussion leader. In this course, a different 
triad was responsible for facilitating each weekly discussion. The role of the e-moderators was to stimulate discussion, keep the discussion on topic, encourage everyone to participate, and summarise the weekly discussion. Despite building this aspect of teaching presence into the course, learners did not feel that the discussions reached critical thinking. Our findings support Garrison et al.'s (2001) claims that cognitive presence requires guidance, support, and nurturing; it does not just happen. An educational environment "must be more than undirected, unreflective, random exchanges and dumps of opinions" (Garrison et al., 2001, p.21). Garrison (2006) later clarified that "direction and facilitation is [sic] required to establish cohesion and ensure messages are developmental" (p. 4). Furthermore, learners should understand "the stages of inquiry and how this relates to the task at hand" (Garrison, p. 5). Examining the data in light of the community of inquiry framework suggests that several of the weaknesses regarding the discussion might have been addressed with more active facilitation of the online discussions. On reflection, we question whether the learners were equipped to take on this role and had the necessary skills and understanding to cultivate higher level thinking in these forums. In their study of collaborative interactions in three online courses, Pawan et al. (2003) concluded that "students require training and modelling by instructors before they can assume the roles [of facilitation and leadership] in an effective manner" (p. 136). Once again, as online educators, it becomes apparent that we need to ensure the learners have the requisite skills and/ or support and guidance to lead online discussion if we are going to ask them to take on that role (Rourke \& Anderson, 2002). Moreover, there is a need for the instructor to take on a "meta-facilitation" role. Delegating moderating responsibilities to the learners requires ongoing support and coaching by the instructor. As this inquiry illustrates, the instructor must still retain responsibility for the overall facilitation of the online experience. If not, the success of the learning experience is jeopardised.

Although the professors logged on multiple times each day, read every posting, and responded immediately when there was a question, concern, or problem, they did not post every day. When they did, the posting usually referred to what had gone on in the course in the preceding few days and was often long. It became apparent in this course that the learners wanted the professors to be more visible by way of more frequent postings. However, this can quickly become time consuming and unfeasible. Garrison and Cleveland-Innes (2005) noted, "It is not educationally desirable or reasonable from a time-management perspective to have the teacher respond to each comment. But it is crucial that the teacher moderate and shape the direction of the discourse" (p. 145). Similarly, Pawan et al. (2003) recommended that instructors model the type of postings they expect from learners. They suggested that long postings (300 words or more), and those posted all at one time, imply a presentation mode rather than a discussion mode.

Time is a definite issue for instructors in online courses (MacDonald, Stodel, Coulson, Mace, \& Thompson, in press; Muilenburg \& Berge, 2001). As a professor with 25 years of teaching experience, the third author has never spent the time and energy in any F2F class that she has in designing and delivering online courses. Hiltz (1988) compared teaching online to parenthood: "You are on duty all the time, and there seems to be no end to the demands on your time and energy" (p. 441). Is this degree of investment necessary to make online learning effective or are we going beyond the call of duty to ensure we are successful and setting unrealistic expectations for ourselves?

In terms of direct instruction, the two professors provided intellectual and scholarly leadership and shared their subject matter knowledge with learners by providing synthesised text-based content in weekly e-Docs, providing detailed feedback on assignments using the "track changes" feature in Word, answering questions through email and the discussion forums, and participating 
in online discussions. Nonetheless, despite the fact the learners reported they had never received so much feedback on assignments, the content was relevant and meaningful, and the professors' responses to questions were quick and helpful, some learners felt they were not receiving full advantage of the professors' expertise. Learners did not seem to link these contributions with teacher expertise. This raises questions regarding learner expectations and the need for a paradigm shift to separate the underlying learning assumptions of online learning from classroom learning. Are learners' expectations for online learning higher than they are for F2F learning?

Overall, the learners appreciated the availability and support of the professors. Our findings also point to the importance of providing learners with confirmation they are on track in the course. New issues related to online learning came into view and prompted us to question whether learners' (and instructors') expectations with regards to teaching presence in terms of design and organisation, facilitating discourse, and direct instruction are realistic. If they are not, it may be problematic given the abundance of research that suggests "teaching presence is a significant determinate of student satisfaction, perceived learning, and sense of community" (Garrison, 2006, Teaching Presence section, \$2). The way we define our roles as teachers and learners and our attitudes, practices, and expectations need to be fundamentally different in an online context compared to F2F. We need to understand these elements if we are to transform education and liberate the way we design and deliver online learning.

\section{Limitations}

There are several limitations to this research. First, the perspectives reported in this paper are those of the learners who indicated they missed and/ or would have liked more F2F contact in the course. It is not known whether efforts made to address these learners' concerns would contribute or detract from other learners' experiences. A comparative case study using a multi-method approach that examines the perspectives of both learners who did and did not miss F2F contact is warranted. Understanding why some learners missed F2F contact whereas others did not, and the characteristics that distinguish these groups, would be valuable. A more in-depth examination of how those learners who missed F2F contact felt it impacted their learning would also be of interest.

Second, differences in preferred communication and learning styles as a result of gender-related or cultural issues were not examined in this inquiry. Future research examining the role of gender, ethnicity, and culture on online learning preferences is required. Lastly, the learners were interviewed by the co-professor, which may have prevented full disclosure by the participants. We tried to mitigate this concern by conducting the interviews after the learners' grades had been submitted. In addition, the interviewer was not responsible for grading the learners' work. The transcripts reveal that the learners were forthcoming in their responses and did not appear reticent to comment on negative aspects of the course or the professors.

\section{Implications for Practice}

Using the community of inquiry framework to interpret our findings provided us with new understandings regarding online learning. We were able to view this course from an alternative perspective and see the online experience in a new light. As the import of presence in an online environment was revealed, it became apparent that aspects of what online learners miss about F2F learning relate to deficiencies in presence. As a result, a number of recommendations for improving practice emerged: 


\section{Create opportunities to enhance spontaneity and emergent design}

Allow flexibility in the course design and facilitation to ensure responsiveness to learners' needs as they emerge. Collaborative authoring tools, such as wikis and blikis, enable learners to build the course content in ways that are interesting and meaningful to them. Learners bring their ideas into a learning space that they are constructing. The fluid and spontaneous linking structure of wikis enables a non-linear and more playful representation of key learnings and allows the pursuit of interesting tangents. In essence, the learners assume a more active role in co-constructing the learning elements. However, enabling this "freedom" presumes a comfort level in the instructor, as well as the required skills, to work with emergent developments. From a technology perspective, the use of synchronous communication tools will help promote spontaneity. However, spontaneity can also be fostered in an asynchronous environment. The incorporation of IVR systems will allow learners to dictate postings, thereby reinstating the possibility for spontaneity in communication. Features that indicate when other learners are online will also serve to promote opportunities for spontaneous conversations.

\section{Coach learners how to learn online}

Online learning is a fundamentally new learning experience. Just as educators need to learn how to teach online, learners need to learn how to learn online. It is important to create spaces within an online learning event that invite learners to reflect on how they are bound by discourses and practices from a traditional F2F classroom that extend back to kindergarten days-boundaries that include expectations about what learning is, what teaching is, how a learning experience should unfold, and the roles assumed by teacher and learner. It is to be expected that F2F practices will be adopted and transposed into an online learning environment to some degree. At issue is a largely unexamined or unconscious transfer of F2F classroom practices to the online environment. Thomas (2002) warned that major difficulties arise from the conflict between form and function when we expect the "text-based medium of the online discussion forum" to serve the function of F2F interaction rather than presenting a "technology-mediated alternative to F2F dialogue" (p. 363).

What became apparent from this inquiry is that developing and maintaining community, which entails being able to communicate effectively online as well as facilitate online dialogue, is a critical skill for online learners. Learners need to shift their focus from an individual perspective to one of community. Facilitators need to be prepared for the role they must take in actively guiding the online discussions in order to achieve the desired quality of interaction. Educators should articulate best practices, be role models in their online interactions, provide examples of strong community building behaviours, remind learners of the important role they have in the discussions, offer constructive feedback, and be present to coach and support learners in their interactions. We cannot assume that effective communication and facilitation will just happen, even with a thoughtful course design. As this inquiry illustrates, teaching presence (as outlined in the community of inquiry framework) is the responsibility of every participant in an online environment.

\section{Explore the use of diverse technologies for enhancing communication and social presence}

Over a decade ago, Berge and Collins (1995) pointed to the fact that educators often do not take advantage of the latest technologies available to enhance learning. They argued, "there is no 
shortage of technology, only a shortage of the educational vision necessary to use the technology to create new educational environments" (p. 5). Indeed, communication in online courses has commonly been limited to text-based discussion forums. However, as Thomas (2002) cautioned, "the attainment of a discourse that is both interactive and academic in nature is difficult within the online environment of the traditional threaded discussion" (p. 359). The present inquiry further revealed that threaded discussions can make it hard to inject emotion into communication, make others salient in the learning environment, and foster enjoyable and rewarding interactions. The ever-present tension is juggling the demand for academic discourse while at the same time desiring personal expression and connection on an individual level. Boyd (2006) proposed learners, "write themselves into being online" (p. 9). However, there are other effective means of communicating online that are not so dependent on "writing" ourselves into being. Technologies, such as Web-based audio- and video-conferencing and application sharing, that do not rely on text might be more effective at establishing social presence and supporting richer communication. Finally, learners should be encouraged to communicate with each other outside the formal venue of the online course whenever possible so they can benefit from F2F interactions and/ or synchronous interactions as needed or desired.

\section{Articulate and manage the expectations of the online community}

Expectations of both the learners and instructors in online environments need to be discussed and made explicit. Much of this discussion should focus on the process of learning and the best way to achieve the learning objectives both as a group as well as individually. Is a community going to be developed and, if so, what is its purpose: To create a social infrastructure to support the learners, to foster critical thinking, or a combination of both? As the concept of community is complex and usually not clearly articulated it should be unpacked and examined with particular attention to why a course designer, instructor, or learner believes it is (or is not) important in the learning process.

\section{Understand all learners in online learning environments}

Not everyone embraces learning in an online environment. Many learners have a choice about whether or not to take their course or program online. Others do not. The present inquiry revealed that learners can be successful in online courses in terms of learning outcomes, yet still long for a richer experience. Also illustrated is the need to understand learners in order to help them develop coping and adaptation strategies so that the online learning experience is effective and enjoyable. As educators, we must continue to focus on how we can help each learner feel comfortable and confident in the online environment, especially when it is not his or her preferred learning medium, even when the obvious indicators of success are present.

\section{Conclusion}

Using the community of inquiry framework (Garrison et al., 2000) to interpret the findings in this inquiry brought the significance of presence, in its many different guises, to the fore and also served to emphasise the importance of questioning the commitment of the participants to the creation of a community of critical inquiry, a community expressed and brought to life in the space created by online text-based discussions. Furthermore, as this inquiry revealed, the three "presences" outlined in Garrison et al.'s (2000) framework are not distinct dimensions. While it is valuable to scrutinise each singly, a deeper understanding of how they interrelate is needed. 
Through this inquiry we discovered something about what it is that learners miss about F2F contact when they are learning online and the dangers inherent in transposing our comfortable and familiar F2F practices and expectations into the new medium. Expecting an online learning experience to be a 'copy' of other learning experiences (i.e., F2F) is potentially problematic. If it is not the same does that necessarily make it a lesser experience? Burbules and Callister (2000) suggested that rich online activities are "unique and irreplaceable learning opportunities themselves; and often they can exist only online" (p. 277). Our online learning experiences in cyberspace are filled with paradoxes. Idhe (1990) pointed out the contradiction that the "user both wants and does not want the technology. The user wants what the technology gives but does not want the limits" (p. 76). This discussion is a reminder that as technology magnifies and reduces it draws attention to what is present as well as what is missing.

\section{References}

Anagnostopoulos, D., Basmadjian, K. G., \& McCrory, R. S. (2005). The decentered teacher and the construction of social space in the virtual classroom. Teachers College Record, 107(8), 1699-1729.

Anderson, T. (2004). Teaching in an online learning context. In T. Anderson \& F. Elloumi (Eds.) Theory and practice of online learning (pp. 273-294). Athabasca, AB.: Athabasca University. Retrieved November 8, 2006 from: http://cde.athabascau.ca/online_book/

Anderson, T., \& Elloumi, F. (2004). Theory and practice of online learning. Athabasca, AB.: Athabasca University. Retrieved November 8, 2006 from: http://cde.athabascau.ca/online book/

Anderson, T., Rourke, L., Garrison, D. R., \& Archer, W. (2001). Assessing teaching presence in a computer conferencing context. Journal of Asynchronous Learning Networks, 5(2), 1-17.

Aragon, S. R. (2003). Creating social presence in online environments. New Directions for Adult and Continuing Education, 100, 57-68.

Argyle, M., \& Dean, J. (1965). Eye contact, distance, and affiliation. Sociometry, 28(3), 289-304.

Berge, Z. L., \& Collins, M. P. (Eds.) (1995). Computer Mediated Communication and the Online Classroom Vol. III. Distance learning. Cresskill, NJ.: Hampton Press.

Bibeau, S. (2001). Social Presence, Isolation, and Connectedness in Online Teaching and Learning. From the literature to real life. Journal of Instruction Delivery Systems, 15(3), 35-39.

Bogdan, R. C., \& Biklen, S. K. (1998). Qualitative research for education (3rd Ed.) Toronto: Allyn \& Bacon.

Boyd, D. (2006, March 9-6). G/localization: When global information and local interaction collide. Paper presented at the O'Reilly Emerging Technology Conference. Retrieved August 1, 2006 from: http://www.danah.org/papers/Etech2006.html 
Burbules, N. C., \& Callister, T. A. (2000). Universities in Transition: The promise and the challenge of new technologies. Teachers College Record, 102(2), 271-293.

Burge, E. J., \& Haughey, M (2001). Using Learning Technologies: International perspectives on practice. London: Routledge Falmer.

Cavallo, D. (2000). Emergent Design and Learning Environments: Building on indigenous knowledge. IBM Systems Journal, 39(3\&4). Retrieved August 11, 2004 from: http://www.research.ibm.com/journal/sj/393/part2/cavallo.html

DeBard, R., \& Guidera, S. (2000). Adapting asynchronous communication to meet the seven principles of effective teaching. Journal of Educational Technology Systems, 28(3), 219230.

Dewey, J. (1933). How we think. Boston: DC Heath.

Eggins, S., \& Slade, D. (1997). Analyzing casual conversation. Washington, DC.: Cassell.

Garrison, D. R. (2006). Online community of inquiry update: Social, cognitive, and teaching presence issues. Unpublished paper. Retrieved May 17, 2006 from: http://communitiesofinquiry.com/sub/papers.html

Garrison, D. R., \& Anderson, T. (2000). Transforming and Enhancing University Teaching: Stronger and weaker technological influences. In T. Evans \& D. Nation (Eds.) Changing University Teaching: Reflections on creating educational technologies (pp. 24-33). London: Kogan Page.

Garrison, D. R., Anderson, T., \& Archer, W. (2000). Critical Inquiry in a Text-based Environment: Computer conferencing in higher education. Internet and Higher Education 2(2-3), 87-105.

Garrison, D. R., Anderson, T., \& Archer, W. (2001). Critical thinking, cognitive presence, and computer conferencing in distance education. American Journal of Distance Education 15(1), 7-23.

Garrison, D. R., \& Cleveland-Innes, M. (2005). Facilitating Cognitive Presence in Online Learning: Interaction is not enough. American Journal of Distance Education, 19(3), 133-148.

Garrison, D. R., Cleveland-Innes, M., Koole, M., \& Kappelman, J. (2006). Revisiting Methodological Issues in the Analysis of Transcripts: Negotiated coding and reliability. Internet and Higher Education, 9(1), 1-8.

Gunawardena, C. N. (2005, July-August). Social presence and implications for designing online learning communities. Paper presented at the Fourth International Conference on Educational Technology, Nanchang, China. 
Gunawardena, C. N., \& Zittle, F. J. (1997). Social presence as a predictor of satisfaction within a computer-mediated conferencing environment. American Journal of Distance Education, 11(3), 8-26.

Haythornthwaite, C., Kazmer, M. M., Robins, J., \& Shoemaker, S. (2004). Community development among distance learners: Temporal and technological dimensions. In C. Haythornthwaite \& M. M. Kazmer (Eds.) Learning, culture and community in online education: Research and practice (pp. 35-57). New York: Peter Lang.

Hiltz, R. S. (1988). Learning in a Virtual Classroom: Final evaluation report 25. Newark, NJ.: Computerized Conferencing and Communications Center.

Idhe, D. (2004). A phenomenology of technics. In D. M. Kaplan (Ed.) Readings in the philosophy of technology (pp. 137-159). Lanham, MD.: Rowman \& Littlefield.

Kanuka, H., Collett, D., \& Caswell, C. (2002). University instructor perceptions of the use of asynchronous text-based discussion in distance education courses. American Journal of Distance Education, 16(3), 151-167.

Levy, P. (2003). A methodological framework for practice-based research in networked learning. Instructional Science, 31(1-2), 87-109.

Lobry de Bruyn, L. (2004). Monitoring Online Communication: Can the development of convergence and social presence indicate an interactive learning environment? Distance Education, 25(1), 67-81.

MacDonald, C. J., Stodel, E. J., Coulson, I., Mace, H., \& Thompson, T-L. (in press). Pioneers in eLearning: Exploring different technologies.

MacDonald, C. J., Stodel, E. J., Farres, L.G., Breithaupt, K., \& Gabriel, M. A. (2001). The Demand-Driven Learning Model: A framework for web-based learning. Internet and Higher Education, 1(4), 9-30.

MacDonald, C. J. \& Thompson, T-L. (2005). Structure, Content, Delivery, Service, and Outcomes: Quality e-Learning in higher education. International Review of Research in Open and Distance Learning, 6(2). Retrieved May 17, 2005 from: http://www.irrodl.org/index.php/irrodl/article/view/237/321

McConnell, D. (2002). The experience of collaborative assessment in e-learning. Studies in Continuing Education, 23(1), 73-92.

Merriam, S. B. (1998). Qualitative research and case study applications in education. San Francisco, CA.: Jossey-Bass.

Muilenburg, L. Y., \& Berge, Z. L. (2001). Barriers to Distance Education: A factor-analytic study. American Journal of Distance Education, 15(2), 7-22. 
Pawan, F., Paulus, T. M., Yalcin, S., \& Chang, C-F. (2003). Online Learning: Patterns of engagement and interaction among in-service teachers. Language Learning and Technology, 7(3), 119-140.

Rogers, P., \& Lea, M. (2005). Social Presence in Distributed Group Environments: The role of social identity. Behaviour and Information Technology, 24(2), 151-158.

Rourke, L., Anderson, T., Garrison, D. R., \& Archer, W. (1999). Assessing social presence in asynchronous text-based computer conferencing. Journal of Distance Education, 14(2). Retrieved February 10, 2006 from: http://cade.athabascau.ca/vol14.2/rourke_et_al.html

Rourke, L., \& Anderson, T. (2002). Using peer teams to lead online discussions. Journal of Interactive Media in Education, 1, 1-21.

Rovai, A. P. (2002). Building sense of community at a distance. International Review of Research in Open and Distance Learning, 3(1). Retrieved May 17, 2006 from: http://www.irrodl.org/index.php/irrodl/article/view/79/153

Rovai, A. P. (2003). A practical framework for evaluating online distance education programs. Internet and Higher Education, 6(2), 109-124.

Russo, T. C., \& Campbell, S. W. (2004). Perceptions of Mediated Presence in an Asynchronous Online Course: Interplay of communication behaviours and medium. Distance Education, 25(2), 215-232.

Salmon, G. (2000). E-moderating: The key to teaching and learning online. London: Kogan Page.

Schwandt, T. A. (1994). Constructivist, interpretivist approach to human inquiry. In N. K. Denzin \& Y. S. Lincoln (Eds.) Handbook of qualitative research (pp. 118-137). Thousand Oaks, CA.: Sage.

Shamp, S. (1991). Mechanomorphism in perception of computer communication partners. Computers in Human Behavior, 7(3), 147-161.

Shin, N. (2002). Beyond Interaction: The relational construct of 'Transactional Presence.' Open Learning, 17(2), 121-137.

Short, J., Williams, E., \& Christie, B. (1976). The social psychology of telecommunications. Toronto, ON.: Wiley.

Song, L., Singleton, E. S., Hill, J. R., \& Koh, M. H. (2004). Improving online learning: Student perceptions of useful and challenging characteristics. Internet and Higher Education, 7(1), 59-70.

Stroupe, C. (2003). Making Distance Presence: The compositional voice in online learning. Computers and Composition, 20, 255-275.

Thomas, M. J. W. (2002). Learning within incoherent structures: The space of online discussion forums. Journal of Computer Assisted Learning, 18(3), 351-366. 
Thompson, T-L., \& MacDonald, C. J. (2005). Community Building, Emergent Design, and Expecting the Unexpected: Creating a quality eLearning experience. Internet and Higher Education, 8, 233-249.

Tu, C-H., \& McIsaac, M. (2002). The relationship of social presence and interaction in online classes. American Journal of Distance Education, 16(3), 131-150.

Wang, A.Y., \& Hewlin, M.H. (2001, August). Online Lectures: Benefits for the virtual classroom. T.H.E. Journal. Retrieved April 14, 2006 from: http://www.thejournal.com/articles/15513

Wiener, M., \& Mehrabian, A. (1968). Language within Language: Immediacy, a channel in verbal communication. New York: Appleton-Century-Crofts.
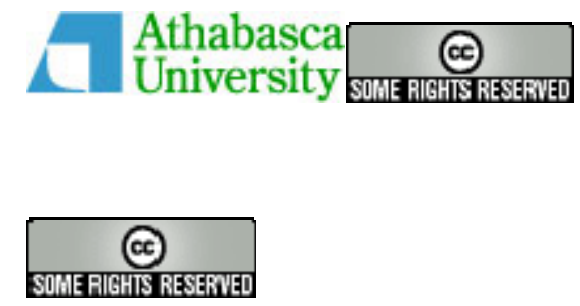